\title{
A New Air Displacement Plethysmograph for the Measurement of Body Composition in Infants
}

\author{
ALESSANDRO URLANDO, PHILIP DEMPSTER, AND SUSAN AITKENS
}

Life Measurement Incorporated, Concord, CA 94520, U.S.A.

\begin{abstract}
This article introduces and evaluates the PEA POD Infant Body Composition System, an air displacement plethysmograph designed for the assessment of body composition in infants between birth and 6 mo of age. The performance of the PEA POD was evaluated by repeated testing of National Institute of Standards and Technology-traceable weights and volumes. Mass was measured in a single session. Volume was measured in four sessions during a 2-d period (five times/session for both). The mean values for repeated mass measurements were almost identical to the masses of traceable weights. The SD and CV for repeated volume measurements were 1.1-4.5 $\mathrm{mL}$ and $0.02-$ $0.09 \%$, respectively. Both the mean SD and CV were within very narrow ranges (1.4-3.1 $\mathrm{mL}$ for $\mathrm{SD}$ and $0.03-0.08 \%$ for $\mathrm{CV}$ ) across all volume levels. Furthermore, mean $\mathrm{CV}$ values using results from the four sessions indicated excellent within- and between-day reliability. Regression analyses (by session or with all sessions combined) of the measured volume against actual volume gave very low standard error of the estimate (SEE) (0.853-1.957 $\mathrm{mL})$ and very high $\mathrm{R}^{2}(1.000)$, with the intercept and slope not significantly different from 0 and 1 , respectively.
\end{abstract}

\section{ABSTRACT}

The mean percentage error in volume measurements was $\leq 0.05 \%$ at all volume levels. The study findings and the operational and physical characteristics of the system indicate that the PEA POD has the potential to provide clinicians and researchers with a diagnostic and research tool that is accurate, easily used by operators, and comfortable for subjects. (Pediatr Res 53: 486492, 2003)

Abbreviations
HD, hydrodensitometry
ADP, air displacement plethysmography
NIST, National Institute of Standards and Technology
SAA, surface area artifact
BSA, body surface area
$\mathbf{V}_{\mathbf{T G}}$, thoracic gas volume
FRC, functional residual capacity
$\mathbf{V}_{\mathbf{T}}$, tidal volume
$\%$ fat, percentage fat mass
$\mathbf{C V}$, coefficient of variation

The prevalence of obesity in adults and children continues to rise $(1,2)$. A total of $61 \%$ of the US adult population is now considered overweight or obese (1); $13 \%$ of the US children are obese (2), putting them at a higher risk for adult obesity (3). Strong links also exist between early infant development and childhood obesity (4). In addition to its great affect on the quality of life, obesity is associated with serious health risks (5, 6). The assessment of body composition throughout life is therefore an important diagnostic and research tool.

In recent years, novel technologies have resulted in the development of new body composition methods (7). Some of these methods have been applied to the infant population (8). However, technological and practical limitations have ham-

Received April 3, 2002; accepted November 6, 2002.

Correspondence: Alessandro Urlando, 1850 Bates Avenue, Concord, CA 94520, U.S.A.; e-mail: aurlando@bodpod.com

The research for this manuscript was supported by NIH Small Business Innovative Research Grants \# R43DK50021-01 and \# R43DK50021-02 from the National Institute of Diabetes and Digestive and Kidney diseases (NIDDK). The authors are employees of Life Measurement, Inc., the grant recipient.

DOI: 10.1203/01.PDR.0000049669.74793.E3 pered the success of these new methods to the point that body composition assessment in infants is still rarely performed.

All body composition methods used to test live subjects are indirect. As a result, each method is based on a theoretical model, which is used to assess body composition from indirect measurements. Therefore, the accuracy of a body composition method is dependent on the soundness of its theoretical model and the assumptions surrounding the said model. In light of this, when selecting a method to assess body composition in infants, its accuracy in other populations must be considered because it is representative of the method's theoretical soundness. Densitometry is considered to be among the most accurate indirect body composition method (9). A densitometric approach to infant body composition assessment could therefore have the potential for high measurement accuracy.

Body composition assessment by densitometry involves the measurement of the density of the whole body. Body density is then used in a two-compartment model to calculate percentage of fat, fat mass, and fat free mass $(10,11)$. By definition, the density of the whole body is body mass divided by body 
volume. Body mass is easily measured using an accurate weighing device. Body volume is a more difficult measurement and is commonly determined either by hydrodensitometry (HD) or air displacement plethysmography (ADP). HD measurement procedures are performed in water. ADP measurement procedures are performed in air. This difference is the result of the different operating principles used by the two methods. HD uses Archimedes' principle to determine body volume. ADP uses gas laws to determine body volume. Because HD requires subjects to be totally submerged during a test, compliance and safety issues prevent the implementation of this technique in the infant population. Conversely, the use of ADP in children and the elderly $(9,12)$ has demonstrated that its measurement procedures are easily tolerated in these populations and would probably be tolerated by infants.

The only commercially available ADP system is the BOD POD Body Composition System (Life Measurement Inc., Concord, CA, U.S.A.). The success of the BOD POD has prompted the development of the PEA POD Infant Body Composition System (Life Measurement Inc.). The PEA POD is intended to provide researchers and clinicians with an infant body composition system that is accurate and easily used by operators as well as comfortable for the subjects. The physical characteristics of the system allow the testing of infants between birth and 6 mo of age.

This article first introduces the PEA POD by giving an overview of its theory, physical design, operating principle, and test procedure. The precision, reliability, accuracy, and linearity of the PEA POD mass and volume measurements are then assessed by testing National Institute of Standards and Technology (NIST)-traceable weights and aluminum cylinders.

\section{METHODS}

Theory. The relationships between pressure and volume expressed by Boyle's Law and Poisson's Law are the basis of the operating principles used by the PEA POD to measure body volume. Boyle's Law describes the behavior of air compressed under isothermal conditions (constant temperature) as follows:

$$
\mathrm{P}_{1} / \mathrm{P}_{2}=\mathrm{V}_{2} / \mathrm{V}_{1}
$$

where $P_{1}$ and $V_{1}$ are pressure and volume at an initial condition and $\mathrm{P}_{2}$ and $\mathrm{V}_{2}$ are pressure and volume at a final condition. When air is allowed to change temperature in response to volume changes (adiabatic conditions), Poisson's Law expresses its behavior as follows:

$$
\mathrm{P}_{1} / \mathrm{P}_{2}=\left(\mathrm{V}_{2} / \mathrm{V}_{1}\right)^{\gamma}
$$

For air, $\gamma$ is 1.4 (13).

A consequence of Equations 1 and 2 is that equal volume changes result in different pressure changes for air under isothermal and adiabatic conditions. In air, for small volume changes, $\mathrm{P}_{2}$ under adiabatic conditions is always approximately $40 \%$ larger than $\mathrm{P}_{2}$ under isothermal conditions. Air under isothermal conditions is therefore "easier" to compress than air under adiabatic conditions (14).

Physical design. The PEA POD basic components are housed inside or mounted on a movable cart (Fig. 1). The

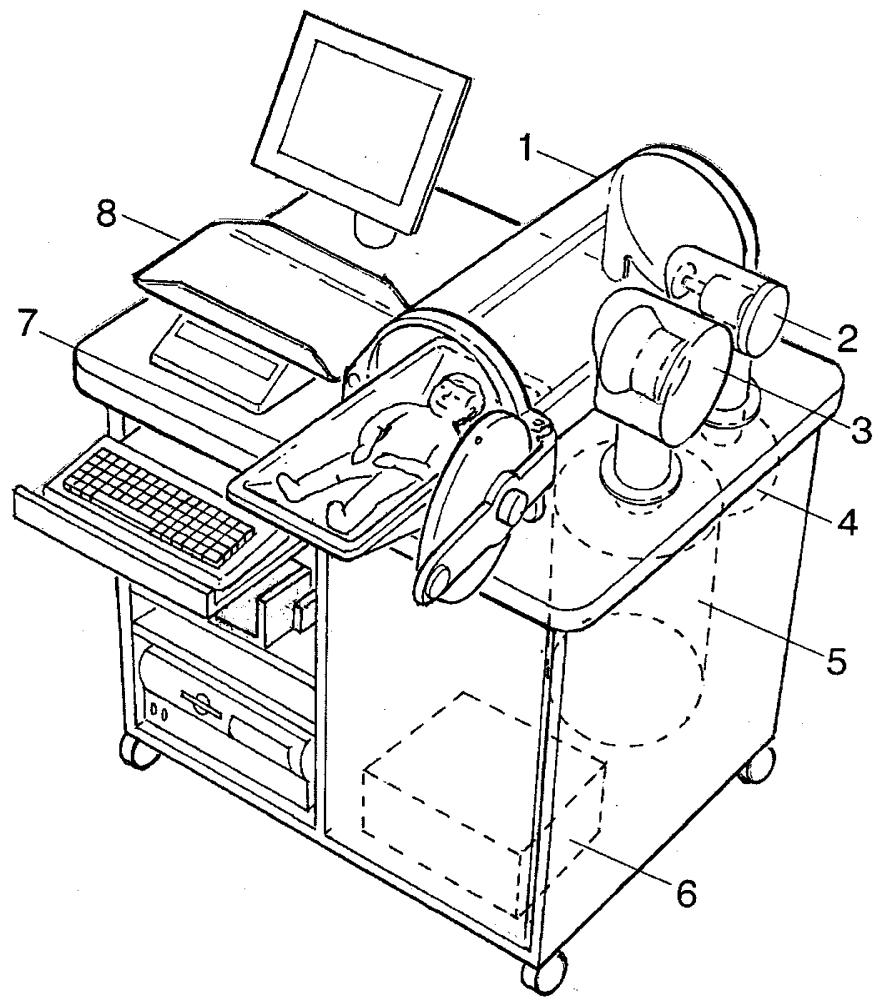

Figure 1. The prototype version of the PEA POD, Body Composition System, used in this study. Numbers refer to the test chamber (1), calibration valve (2), diaphragm (3), calibration volume (4), reference chamber (5), electronics (6), sliding tray (7), and scale (8).

movable cart houses the reference chamber, calibration volume, electronic components, printer, and central processing unit (CPU). The test chamber, scale, and monitor are mounted on the cart's top surface. A volume-perturbing diaphragm is mounted between the test and reference chambers. A pneumatic valve (calibration valve) allows the test chamber to be connected to the calibration volume. Pressure transducers are connected to the two chambers.

The test chamber contains a clear plastic tray on a slide mechanism. The slide mechanism is secured to the inside of a clear acrylic plastic cylinder. A clear sheet of acrylic plastic seals the back of the cylinder. An aluminum door is mounted to the front of the cylinder. During a test, the door is kept closed by an electromagnet.

The test chamber is connected to the reference chamber by an acrylic plastic manifold. However, the two chambers are not in direct contact with each other. The volume-perturbing diaphragm is mounted between them in the manifold. The same design and materials of the test chamber, with the exclusion of the door system, are used for the reference chamber. Furthermore, the two chambers are equal in volume $(37 \mathrm{~L})$.

The test chamber is connected to the calibration volume by an aluminum manifold. The calibration valve is mounted between the test chamber and the aluminum manifold. When the calibration valve is open, the test chamber and calibration volume are in direct contact with each other. The calibration volume consists of a $5 \mathrm{~L}$ aluminum sphere.

The PEA POD scale measures mass using strain gauge technology. The materials used in the scale's strain gauge were 
selected for their stability. The scale has a capacity of $12 \mathrm{~kg}$ and a resolution of $0.1 \mathrm{~g}$. Extensive testing in the scale's weight range for noise, drift, and hysteresis has confirmed the scale's stability.

The CPU and electronic components control the diaphragm, calibration valve, pressure transducers, and scale. A custom designed 16-bit A/D card with a 24 bit programmable I/O port interfaces the CPU and electronic components. Both control and analysis software programs are written in $\mathrm{C}$ Borland (Scott's Valley, CA, U.S.A.).

Operating principles. When in operation, the diaphragm's oscillations create sinusoidal volume perturbations in the two chambers that are equal in magnitude but opposite in sign. The precision of the diaphragm position is maintained by an electronic servo system. The magnitude and frequency of the volume perturbations are $35 \mathrm{~mL}$ and $6 \mathrm{~Hz}$, respectively.

Pressure changes resulting from the volume perturbations are below $\pm 0.5 \mathrm{~cm} \mathrm{H}_{2} \mathrm{O}$. These pressure changes are in "real-world" terms equivalent to the change in atmospheric pressure experienced during an elevation change of $3.87 \mathrm{~m}$ $(12.8 \mathrm{ft})$. The magnitude of the pressure changes in the two chambers is purposely maintained low (atmospheric pressure is approximately $1000 \mathrm{~cm} \mathrm{H}_{2} \mathrm{O}$ ), for comfort, and because, for small pressure changes, the power relationship expressed by Equation 2 is closely approximated by a linear relationship. This means that the ratio of the pressure perturbations in the two chambers is equal to the inverse ratio of the chambers' volumes. Because volumes are assessed by a ratiometric approach, the repeatability of the volume perturbations is not critical as long as their magnitudes are small with respect to the chambers' volumes, thus ensuring that a linear relationship exists between pressure and volume. Therefore, for a known reference chamber volume, and assuming adiabatic conditions, varying test chamber volumes are a linear function of the ratios of the pressure perturbations in the two chambers. However, to ensure measurement accuracy, these volumes must be corrected for the impact of small quantities of air at isothermal conditions.

When a subject is tested, air close to the subject's surface and in the subject's lungs behaves isothermally. Assuming that all of the air in the test chamber is under adiabatic conditions results in an underestimation of the volume being measured. In fact, as previously mentioned, air under isothermal conditions is $40 \%$ more compressible than air under adiabatic conditions. This difference in behavior results in a $40 \%$ overestimation of volumes of air behaving isothermally when adiabatic conditions are assumed. The PEA POD volume measurements are therefore automatically corrected for the impact of the isothermal behavior of air close to the subject's surface and in the subject's lungs.

The impact of air behaving isothermally as a result of its proximity to a surface was investigated by testing aluminum sheets with known volumes and areas. This investigation resulted in the derivation of a constant $k$. This constant was derived so that the product of its multiplication by the surface area of the object being tested would equal the difference between the volume measured by the PEA POD and the object's actual volume, a negative value. This adjustment was defined as the Surface area artifact (SAA) and used to correct PEA POD volume measurements.

When live subjects are tested, the PEA POD automatically corrects for the surface area effect by first computing the subject's body surface area (BSA) and then multiplying BSA by $k$ to obtain the SAA. The following two equations describe this process:

$$
\operatorname{BSA}\left(\mathrm{cm}^{2}\right)=178.27 \cdot \operatorname{Length}(\mathrm{cm})^{0.5} \cdot \operatorname{Weight}(\mathrm{kg})^{0.4838}
$$

$$
\mathrm{SAA}(\mathrm{L})=\mathrm{k}\left(\mathrm{L} / \mathrm{cm}^{2}\right) \cdot \mathrm{BSA}\left(\mathrm{cm}^{2}\right)
$$

The PEA POD uses the Boyd formula (15) to determined BSA (Equation 3). This formula has been shown to be the most accurate in estimating the surface area of infants (16).

When adiabatic conditions are assumed, the apparent volume of air in the lungs is overestimated by $40 \%$. As previously stated, this effect is the result of air being under isothermal conditions in the subject's lungs. Subject's volume is therefore underestimated by $40 \%$ of the subject's thoracic gas volume $\left(\mathrm{V}_{\mathrm{TG}}\right)$. To account for this discrepancy, $\mathrm{V}_{\mathrm{TG}}$ is predicted and $40 \%$ of this value is added to the subject's measured body volume. The PEA POD uses a predicted value for $\mathrm{V}_{\mathrm{TG}}$ because its direct measurement would be too invasive. In addition, only $40 \%$ of any error associated with predicting $\mathrm{V}_{\mathrm{TG}}$ has an effect on body volume. Moreover, $40 \% \mathrm{~V}_{\mathrm{TG}}$ is a small percentage of body volume, further reducing the impact of this correction on the accuracy of the body volume measurement.

During PEA POD testing, subjects breathe normally. This state represents average $V_{T G}$ during tidal breathing. $V_{T G}$ is therefore equal to functional residual capacity (FRC) plus approximately half of tidal volume $\left(\mathrm{V}_{\mathrm{T}}\right)$. Historically, FRC has been measured using either helium dilution or plethysmographic assessment. Helium dilution assessment of FRC in infants routinely gives lower values than those measured by plethysmography (17). This difference results from trapped air in the lungs that cannot be detected by helium dilution (17). The PEA POD uses a FRC prediction equation derived by plethysmographic assessment because any air in the lungs free or trapped is not part of the subject's body volume. The following equation is used to predict FRC because it was derived recently using data from multiple centers (18):

$$
\mathrm{FRC}(\mathrm{mL})=2.36 \cdot \operatorname{Length}(\mathrm{cm})^{0.75} \cdot \operatorname{Weight}(\mathrm{kg})^{0.63}
$$

$\mathrm{V}_{\mathrm{T}}$ values used by the PEA POD were also consolidated from multiple studies (19). These values depend on age and body mass and are equal to $7 \mathrm{~mL} / \mathrm{kg}$ at birth, $9 \mathrm{~mL} / \mathrm{kg}$ at $3 \mathrm{mo}$, $9.3 \mathrm{~mL} / \mathrm{kg}$ at $6 \mathrm{mo}$, and $9.5 \mathrm{~mL} / \mathrm{kg}$ at $12 \mathrm{mo} \mathrm{(20).} \mathrm{Interpolation}$ is used when $V_{T}$ values need to be calculated at ages other than those presented. After $\mathrm{V}_{\mathrm{T}}$ is determined, half of it is added to FRC to obtain $V_{\mathrm{TG}}$.

The PEA POD uses the SAA and $\mathrm{V}_{\mathrm{TG}}$ expressed in liters to correct directly measured raw body volume $\left(\mathrm{V}_{\mathrm{br}}\right)$. Body volume $\left(\mathrm{V}_{\mathrm{b}}\right)$ is computed as follows:

$$
\mathrm{V}_{\mathrm{b}}(\mathrm{L})=\mathrm{V}_{\mathrm{br}}(\mathrm{L})-\mathrm{SAA}(\mathrm{L})+40 \% \mathrm{~V}_{\mathrm{TG}}(\mathrm{L})
$$


Table 1. Descriptive statistics for repeated mass measurements (5 times/session) of NIST-traceable weights in a single session

\begin{tabular}{cccc}
\hline Actual mass $(\mathrm{g})$ & Mean $(\mathrm{g})$ & $\mathrm{SD}(\mathrm{g})$ & $\mathrm{CV}(\%)$ \\
\hline 1000.0 & 1000.0 & 0.0 & 0.00 \\
5000.0 & 5000.1 & 0.0 & 0.00 \\
10000.0 & 9999.9 & 0.1 & 0.00 \\
\hline
\end{tabular}

Table 2. Precision of PEA POD volume measurements (5 times/session) of NIST-traceable aluminum cylinders in four sessions during a 2-D period

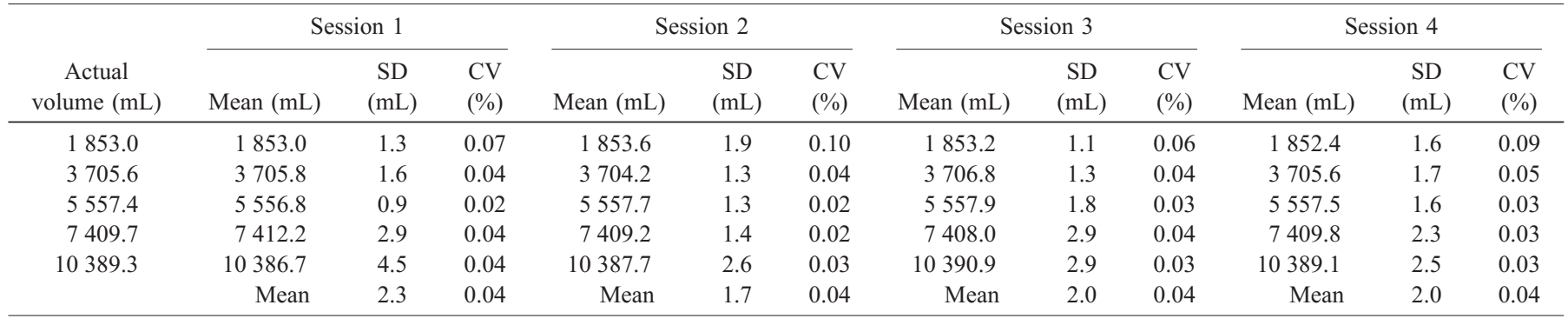

Table 3. Within-day and between-day reliability of volume measurements

\begin{tabular}{ccccc}
\hline $\begin{array}{c}\text { Volume } \\
(\mathrm{mL})\end{array}$ & $\begin{array}{c}\text { Within-day reliability } \\
\text { (sessions 1 and 2) } \\
{[\mathrm{CV}(\%)]}\end{array}$ & $\begin{array}{c}\text { Within-day reliability } \\
\text { (sessions 3 and 4) } \\
{[\mathrm{CV}(\%)]}\end{array}$ & $\begin{array}{c}\text { Between-day reliability } \\
\text { (sessions 1 and 3) } \\
{[\mathrm{CV}(\%)]}\end{array}$ & $\begin{array}{c}\text { Between-day reliability } \\
\text { (sessions 2 and 4) } \\
{[\mathrm{CV}(\%)]}\end{array}$ \\
\hline 1853.0 & 0.05 & 0.08 & 0.05 & 0.02 \\
3705.6 & 0.05 & 0.04 & 0.02 & 0.05 \\
5557.4 & 0.02 & 0.03 & 0.05 & 0.01 \\
7409.7 & 0.04 & 0.02 & 0.03 & 0.01 \\
10389.3 & 0.03 & 0.02 & 0.04 & 0.02 \\
All volumes & 0.04 & 0.04 & 0.04 \\
\hline
\end{tabular}

Within-day reliability is presented for day 1 (sessions 1 and 2) and day 2 (sessions 3 and 4). Between-day reliability is presented for session 1 of day 1 and session 3 of day 2, as well as session 2 of day 1 and session 4 of day 2. Reliability is expressed as the mean of the CV values for each repeated trial performed on a particular volume or volumes in the specified sessions.

Table 4. Regression of volume measurements by PEA POD versus actual volumes calculated from the NIST-traceable cylinders' linear dimensions

\begin{tabular}{lcccccc}
\hline Session & Regression equation* & Adj. $\mathrm{R}^{2}$ & $\mathrm{P}$ & $\mathrm{SEE}(\mathrm{mL})$ & Slope $\neq 1$ & Intercept $\neq 0$ \\
\hline 1 & $\mathrm{~V}_{\mathrm{A}}=1.0002( \pm 0.0003) \mathrm{V}_{\mathrm{M}}-0.9688( \pm 1.9238)$ & 1.0000 & $<0.0001$ & 1.9573 & NO $(\mathrm{P}=0.5636)$ & $\mathrm{NO}(\mathrm{P}=0.6492)$ \\
2 & $\mathrm{~V}_{\mathrm{A}}=1.0002( \pm 0.0001) \mathrm{V}_{\mathrm{M}}-0.4622( \pm 0.8586)$ & 1.0000 & $<0.0001$ & 0.8536 & NO $(\mathrm{P}=0.2660)$ & NO $(\mathrm{P}=0.6277)$ \\
3 & $\mathrm{~V}_{\mathrm{A}}=1.0000( \pm 0.0002) \mathrm{V}_{\mathrm{M}}-0.1625( \pm 1.4793)$ & 1.0000 & $<0.0001$ & 1.5053 & NO $(\mathrm{P}=0.9233)$ & NO $(\mathrm{P}=0.9195)$ \\
4 & $\mathrm{~V}_{\mathrm{A}}=1.0000( \pm 0.0000) \mathrm{V}_{\mathrm{M}}+0.3565( \pm 0.2995)$ & 1.0000 & $<0.0001$ & 0.3047 & NO $(\mathrm{P}=0.5350)$ & NO $(\mathrm{P}=0.3084)$ \\
$1-4 \dagger$ & $\mathrm{V}_{\mathrm{A}}=1.0001( \pm 0.0000) \mathrm{V}_{\mathrm{M}}+0.3066( \pm 0.5769)$ & 1.0000 & $<0.0001$ & 1.1740 & NO $(\mathrm{P}=0.3858)$ & NO $(\mathrm{P}=0.6016)$ \\
\hline
\end{tabular}

* In the regression, equations $\mathrm{V}_{\mathrm{A}}$ is actual volume, $\mathrm{V}_{\mathrm{M}}$ measured volume, $\mathrm{SEM}$ values are in parenthesis, all values are in $\mathrm{mL}$.

$\dagger$ Data shown are regression analysis results using combined data from all four sessions.

Note that SAA, a negative value by definition, is subtracted from $\mathrm{V}_{\mathrm{br}}$ and $\mathrm{V}_{\mathrm{TG}}$ is added to $\mathrm{V}_{\mathrm{br}}$ to arrive at $\mathrm{V}_{\mathrm{b}}$.

SAA and $40 \% \mathrm{~V}_{\mathrm{TG}}$ each represent approximately $1.5 \%$ of $\mathrm{V}_{\mathrm{b}}$. To illustrate with a typical example, a 1.5 mo-old-male infant in the 50th percentile for weight $(5 \mathrm{~kg})$, length $(57 \mathrm{~cm})$ (19), and \% fat (19.1\%) (21) would have a $V_{b}$ of $4.8876 \mathrm{~L}$, with SAA equal to $0.0744 \mathrm{~L}\left(1.5 \%\right.$ of $\left.\mathrm{V}_{\mathrm{b}}\right)$ and $40 \% \mathrm{~V}_{\mathrm{TG}}$ equal to $0.0620 \mathrm{~L}\left(1.3 \%\right.$ of $\left.\mathrm{V}_{\mathrm{b}}\right)$.

Body mass $\left(\mathrm{M}_{\mathrm{b}}\right)$ and volume measurements are used to calculate whole-body density $\left(\mathrm{D}_{\mathrm{b}}=\mathrm{M}_{\mathrm{b}} / \mathrm{V}_{\mathrm{b}}\right)$. Equations 7 and 8 , based on a two-compartment model, and fat-free mass age and sex specific density values are used to compute percentage of fat mass (\% fat). Existing equations are not used because they were derived using fat-free mass density values specific to the adult population $(10,11)$.

$$
\begin{gathered}
\mathrm{M}_{\mathrm{b}} / \mathrm{D}_{\mathrm{b}}=\mathrm{M}_{\mathrm{f}} / \mathrm{D}_{\mathrm{f}}+\mathrm{M}_{\mathrm{fm}} / \mathrm{D}_{\mathrm{fm}} \\
\% \text { fat }=\left(\mathrm{M}_{\mathrm{f}} / \mathrm{M}_{\mathrm{b}}\right) \cdot 100 \%
\end{gathered}
$$

where $M_{f}$ is fat mass, $D_{f}$ is fat density, $M_{f f m}$ is fat-free mass equal to $\mathrm{M}_{\mathrm{b}}-\mathrm{M}_{\mathrm{f}}$, and $\mathrm{D}_{\text {ffim }}$ is fat-free mass density. Equation 7 is solved for $M_{f}$. This value is then used in Equation 8 to calculate \%fat. To solve Equation 7 for $\mathrm{M}_{\mathrm{f}}, \mathrm{D}_{\mathrm{f}}$ and $\mathrm{D}_{\text {ffm }}$ must be known. $\mathrm{D}_{\mathrm{f}}$ is constant throughout life and equal to 0.9007 $\mathrm{g} / \mathrm{mL}$ (7). $\mathrm{D}_{\mathrm{ffm}}$, however, changes during growth (21). Ageand sex-specific $\mathrm{D}_{\text {ffm }}$ values are used in Equation 7 and are obtained by extrapolating $\mathrm{D}_{\mathrm{ffm}}$ values presented in the literature for boys and girls at $0.5 \mathrm{mo}, 3 \mathrm{mo}, 6 \mathrm{mo}, 9 \mathrm{mo}$, and $12 \mathrm{mo}$ of age. For boys, these values are 1.054, 1.061, 1.062, 1.066, and $1.068 \mathrm{~g} / \mathrm{mL}$ at $0.5 \mathrm{mo}, 3 \mathrm{mo}, 6 \mathrm{mo}, 9 \mathrm{mo}$, and $12 \mathrm{mo}$ of age, 


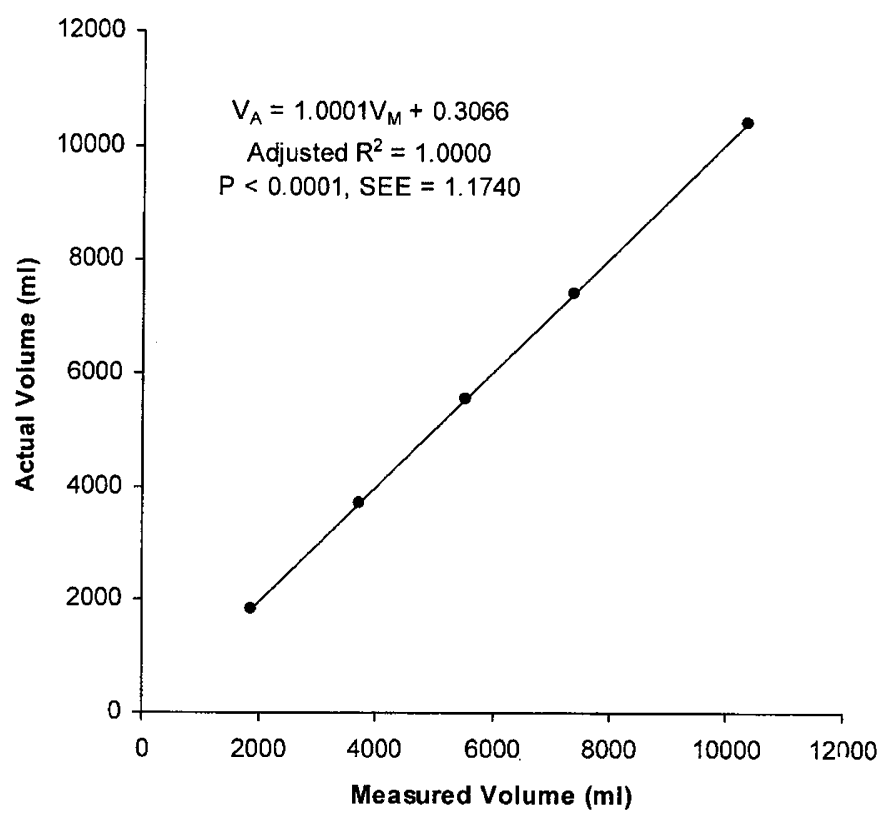

Figure 2. Linear regression of volume measurements by PEA POD (using combined data from all four sessions) versus the NIST-traceable volumes. Solid line is regression equation.

respectively (22). For girls, these values are 1.053, 1.060, $1.062,1.066$, and $1.070 \mathrm{~g} / \mathrm{mL}$ at $0.5 \mathrm{mo}, 3 \mathrm{mo}, 6 \mathrm{mo}, 9 \mathrm{mo}$, and 12 mo of age, respectively (22).

Test procedure. A complete PEA POD test is performed according to the following protocol. The subject's mass is measured on the PEA POD electronic scale. Each time the PEA POD is moved and every $2 \mathrm{wk}$, the mass measurement is preceded by a scale calibration procedure to account for the unlikely possibility of drift in the system and changes in the acceleration as a result of gravity at different geographical locations. A $5000.0 \mathrm{~g}$ NIST-traceable weight is used to calibrate the scale. The scale output is then adjusted in case of a discrepancy. Simultaneous to the mass measurement, an automated volume calibration is performed. With the test chamber empty, pressure changes are collected while the calibration valve is closed and open. The closing and opening of the calibration valve allows the system to perform a two-point calibration giving a linear relationship between the inverse ratio of the pressure perturbations in the two chambers and varying test chamber volumes. The calibration procedure lasts $50 \mathrm{~s}$, at the end of which the door automatically opens. Next, the tray is pulled out of the test chamber so that the subject can be placed in it. To start a test, the tray and subject are pushed back into the chamber, and the door is closed. During the first $15 \mathrm{~s}$ of the test, a valve connecting the test chamber to the outside environment is opened, allowing the exchange of air between the test chamber and the outside environment. This equilibration procedure is performed to avoid temperaturedependent deformations in the test chamber's walls resulting from heat generated by the subject. Pressure changes are then collected in the two chambers for $25 \mathrm{~s}$. Data collection ends with the automatic opening of the test chamber door. This procedure is performed a second time to test for consistency. If the two volume measurements are within $5 \mathrm{~mL}$ of each other or
$0.25 \%$ of the mean of the 2 measurements, whichever is largest, then their mean is used to determine \%fat. If this level of agreement is not reached, then a third measurement is performed. If two of the three measurements agree within the stated limits, then their mean is used to determine \%fat. If the specified level of agreement is not reached after three measurements, then the entire testing procedure is repeated.

Experimental design. First, the ability of the PEA POD to measure mass was determined by testing NIST-traceable weights with the following masses: 1,000.0, 5,000.0, and $10,000.0 \mathrm{~g}$. These weights had NIST 105-1 Class F tolerances $( \pm 100.000 \mathrm{mg})$. The weights tested during this study were representative of infants between birth and 6 mo of age. During a single session, the mass of each weight was measured five times.

Second, the ability of the PEA POD to measure volume was determined by testing aluminum cylinders after they had been added together to obtain the following volumes: 1,853.0, $3,705.6,5,557.4,7,409.7$, and $10,389.3 \mathrm{~mL}$. The accuracy of the linear dimensions of the cylinders tested was $\pm 0.001 \mathrm{~mm}$. This level of accuracy was obtained using instruments traceable to the NIST and in accordance with MIL-I-44208 and MIL-STD-45662A standards. The range of volumes tested $(1,853.0-10,389.3 \mathrm{~mL})$ was selected because it represented infants between birth and 6 mo. Four sets of data were collected over $2 \mathrm{~d}$. Each day was divided into a morning and an afternoon session. All four sessions were performed with the same procedure. During each session, the above volumes were tested five times. Volume testing was performed in four separate sessions so that the reliability of the system could be assessed. Results from sessions performed during the same day gave a measure of within-day reliability. Results from sessions performed during different days gave a measure of betweenday reliability. With the exception of the mass measurement, each test followed the procedure described in the previous section. The BSA values used for the SAA calculations were computed using the cylinders' known dimensions. No correction was performed for $\mathrm{V}_{\mathrm{TG}}$ because it applies only to in vivo testing.

\section{RESULTS}

Mean values, as well as SD and coefficient of variation (CV) values for repeated mass measurements, are presented in Table 1 . In the worst case, mean values differed by $\leq 0.1 \mathrm{~g}$ from the actual mass values. The largest SD was $0.1 \mathrm{~g}$ for the $10,000.00$ $\mathrm{g}$ weight, and the $\mathrm{CV}$ was $0.00 \%$ for each of the three weights tested. Table 2 presents the precision of the volume measurements. The SD and CV for repeated volume measurements within each session were $1.1-4.5 \mathrm{~mL}$ and $0.02-0.09 \%$, respectively. The mean values for both $\mathrm{SD}$ and $\mathrm{CV}$ were within very narrow ranges $(1.7-2.3 \mathrm{~mL}$ for $\mathrm{SD}$ and $0.03-0.08 \%$ for $\mathrm{CV}$ ) across all volume levels. Table 3 presents within- and betweenday reliability of the volume measurements. Within-day reliability is presented for day 1 (sessions 1 and 2) and day 2 (sessions 3 and 4). Between-day reliability is presented for session 1 of day 1 and session 3 of day 2, as well as session 2 of day 1 and session 4 of day 2 . Reliability is expressed as the 
Table 5. MVE, expressed as a percentage of actual volume, across the range of volumes tested

\begin{tabular}{|c|c|c|c|c|c|c|c|c|c|}
\hline \multirow[b]{2}{*}{$\begin{array}{l}\text { Actual volume } \\
\qquad(\mathrm{mL})\end{array}$} & \multicolumn{2}{|c|}{ Session 1} & \multicolumn{2}{|c|}{ Session 2} & \multicolumn{2}{|c|}{ Session 3} & \multicolumn{2}{|c|}{ Session 4} & \multirow{2}{*}{$\begin{array}{c}\text { Sessions } \\
1-4 \\
\text { MVE } \\
(\%)\end{array}$} \\
\hline & $\begin{array}{l}\text { MVE } \\
(\%)\end{array}$ & $\begin{array}{l}\text { SD } \\
(\%)\end{array}$ & $\begin{array}{l}\text { MVE } \\
(\%)\end{array}$ & $\begin{array}{l}\text { SD } \\
(\%)\end{array}$ & $\begin{array}{l}\text { MVE } \\
(\%)\end{array}$ & $\begin{array}{l}\text { SD } \\
(\%)\end{array}$ & $\begin{array}{l}\text { MVE } \\
(\%)\end{array}$ & $\begin{array}{l}\text { SD } \\
(\%)\end{array}$ & \\
\hline 1853.0 & -0.003 & 0.072 & 0.000 & 0.101 & -0.076 & 0.062 & -0.119 & 0.089 & -0.050 \\
\hline 3705.6 & 0.005 & 0.044 & -0.076 & 0.035 & 0.103 & 0.035 & -0.038 & 0.045 & -0.002 \\
\hline 5557.4 & -0.011 & 0.016 & 0.022 & 0.023 & 0.025 & 0.033 & 0.000 & 0.028 & 0.009 \\
\hline Mean & 0.000 & & -0.001 & & 0.008 & & -0.031 & & \\
\hline
\end{tabular}

mean of the $\mathrm{CV}$ values for each repeated trial performed on a particular volume or volumes in the specified sessions. Reliability was excellent with $\mathrm{CV}$ values for all measures of within- and between-day reliability equal to $0.04 \%$ when results for all volumes were combined and $\mathrm{CV}$ values for individual volumes ranging between 0.01 and $0.09 \%$.

Results from linear regression analyses of the PEA POD volume measurements against the volumes calculated from the cylinders' linear dimensions are displayed in Table 4. Data are presented by session and with all four sessions combined. In all cases, the regression equations gave very low SEE (0.3047$1.9573 \mathrm{~mL}$ ) and very high $\mathrm{R}^{2}$ (1.000 for all), with the slope and intercept of all regression lines not significantly different from 1 and 0 , respectively. The regression analysis using combined data from all four sessions is illustrated in Figure 2. As can be seen, the system's linearity was excellent.

Mean volume error (MVE), defined as [(measured volume - actual volume)/actual volume] $\cdot 100$, was computed to investigate further the performance of the system. For all volumes combined, session MVE values ranged between $-0.031 \%$ and $0.008 \%$. Individual MVE values ranged between $-0.119 \%$ and $0.103 \%$. Mean percentage volume errors are presented in Table 5.

\section{DISCUSSION}

For the purposes of this study, the ability of the PEA POD to accurately measure mass and volume were tested independently because errors in either will contribute to errors in \%fat. A $0.1 \%$ error in either mass or volume measurement leads to an error of approximately $0.5 \%$ fat. When both mass and volume are over- or underestimated by the same amount, the \%fat estimation would be unchanged as a result of cancellation of the errors. If the mass and volume errors are in the same direction, then this would equal an error of $1 \%$ fat.

The mean values and the SD and CV for repeated mass measurements presented in Table 1 indicate the exceptional precision and accuracy of the PEA POD scale. As shown in Table 1, the largest mean values differed by $\leq 0.1 \mathrm{~g}$ from the actual mass values, and this would result in changes in \%fat estimates of $\leq 0.1 \%$. The magnitude of these changes points to the measurement of body volume as the limiting factor in the accurate assessment of $\%$ fat.

The SD and CV values for repeated measurements presented in Table 2 indicate a high precision for PEA POD volume measurements. SD values ranged between 1.1 and $4.5 \mathrm{~mL}$, and corresponding $\mathrm{CV}$ values ranged between 0.02 and $0.09 \%$. This level of precision is comparable to that shown by the BOD POD when used to measure the volume of inanimate objects (14) and well above the performance of other body composition methods designed for the infant population and evaluated with inanimate objects (21). The between-day reliability shown by the PEA POD for the range of volumes tested, with mean $\mathrm{CV}$ values ranging from $0.01 \%$ to $0.09 \%$, was comparable to that shown by the BOD POD when used to measure the volume of inanimate objects during a 4-d period (23). Results from linear regression analyses indicate a high agreement between the volumes measured by the PEA POD and the volumes computed from precisely measured linear dimensions. In fact, whether analyzed by session or combined into a single data set, the regression lines did not differ significantly from the line of identity (actual volume $=$ measured volume), indicating an excellent linearity of the system. In addition, the largest MVE recorded corresponds to errors in \%fat estimates of $0.6 \%$. The magnitude of this error is well within the expected measurement variability for densitometry (24).

Even though the PEA POD demonstrates exceptional ability to measure the mass and volume of inanimate objects, this is only the first step. It remains to be seen how the PEA POD performs with respect to the more challenging tasks of testing animal tissue samples varying in mass, volume, and fat content and, most important, living human infants. This research is now under way.

The advantages of the PEA POD include a testing sequence that is noninvasive, is fast, does not expose the subject to radiation, and does not require that the subject be sedated for a test. These characteristics, combined with the accuracy displayed in this study, demonstrate the potential of this technology to assess the body composition of infants. This could lead to the development of a useful tool for researchers and clinicians involved in the nutritional assessment and management of infants.

\section{REFERENCES}

1. National Center for Health Statistics Division of Data Services. Hyattsville, MD National Health and Nutrition Examination Survey (NHANES) 1999 Prevalence of overweight and obesity among adults: United States, 1999. Available at: www.cdc.gov/nchs/products/pubs/pubd/hestats/obese/obse99.htm. Accessed February 7, 2002

2. National Center for Health Statistics Division of Data Services. Hyattsville, MD. National Health and Nutrition Examination Survey (NHANES) 1999 Prevalence of overweight among children and adolescents: United States, 1999. Available at: www.cdc.gov/nchs/products/pubs/pubd/hestats/overwght99.htm. Accessed February 7, 2002 
3. Guo SS, Chumlea WC 1999 Tracking of body mass index in children in relation to overweight in adulthood. Am J Clin Nutr 70:145S-148S

4. Ong KKL, Ahmed ML, Emmett PM, Preece MA, Dunger DB 2000 Association between postnatal catch-up growth and obesity in childhood: prospective cohor study. BMJ 320:967-971

5. Freedman DS, Srinivasan SR, Valdez RA, Williamson DF, Berenson GS 1997 Secular increases in relative weight and adiposity among children over two decades: the Bogalusa Heart Study. Pediatrics 99:420-426

6. Lauer RM, Clarke WR 1989 Childhood risk factors for high adult blood pressure: the Muscatine study. Pediatrics 84:633-641

7. Ellis KJ 2000 Human body composition: in vivo methods. Physiol Rev 80:649-680

8. Koo W 2000 Body composition measurements during infancy. Ann N Y Acad Sci 904:383-392

9. Fields DA, Goran MI 2000 Body composition techniques and the four-compartment model in children. J Appl Physiol 89:613-620

10. Siri WE 1961 Body composition from fluid spaces and density: analysis of methods. In: Bro\&OV0162; eek J, Henschel A (eds) Techniques for Measuring Body Composition. National Academy of Sciences/National Research Council, Washington DC pp 223-224

11. Bro\&OV0162; eek J, Grande F, Anderson JT, Keys A 1961 Densitometric analysis of body composition: revision of some quantitative assumptions. Ann N Y Acad Sci 110:113-140

12. Yee AJ, Fuerst T, Salamone L, Visser M, Dockrell M, Van Loan M, Kern M 2001 Calibration and validation of an air-displacement plethysmography method for estimating percentage body fat in an elderly population: a comparison among compartmental models. Am J Clin Nutr 74:637-642

13. Daniels F, Alberty RA 1967 Physical Chemistry. John Wiley \& Sons Inc, New York, pp $40-44$

14. Dempster P, Aitkens S 1995 A new air displacement method for the determination of human body composition. Med Sci Sports Exerc 27:1692-1697

15. Boyd E 1930 Experimental error inherent in measuring growing human body. Am J Phys Anthropol 13:389-432
16. Wang Y, Moss J, Thisted R 1992 Predictors of body surface area. J Clin Anesth $4: 4-10$

17. Tepper RS, Merth IT, Newth CJL, Gerhardt T 1996 Measurement of functional residual capacity in infants by helium dilution and nitrogen washout. In: Stock J, Sly PD, Tepper RS, Morgan WJ (eds) Infant Respiratory Function Testing. Wiley-Liss, New York, pp 165-189

18. Stocks J, Marchard F, Kraemer R, Gutkowski P, Yishay EB, Godfrey S 1996 Plethysmographic assessment of functional residual capacity and airway resistance. In: Stock J, Sly PD, Tepper RS, Morgan WJ (eds) Infant respiratory function testing. Wiley-Liss, New York, pp 191-239

19. National Center for Health 2001 Statistics in collaboration with the National Center for Chronic Disease Prevention and Health Promotion. Hyattsville, MD. Birth to 36 months: boys length-for-age and weight-for-age percentiles May 30, 2000; modified April 20. Available at: www.cdc.gov/nchs/about/major/nhanes/growthcharts/ set1clinical/cj411017.pdf. Accessed June 24, 2002

20. Stick S 1996 Measurements during tidal breathing. In: Stock J, Sly PD, Tepper RS Morgan WJ (eds) Infant Respiratory Function Testing. Wiley-Liss, New York, pp $117-138$

21. Sheng H-P, Dang T, Adolph AL, Schanler RJ, Garza C 1987 Infant body volume measurement by acoustic plethysmography. In: Ellis KJ, Yasumura S, Morgan WD (eds) In Vivo Body Composition Studies. The Institute of Physical Sciences and Medicine, London, pp 415-420

22. Butte NF, Hopkinson JM, Wong WW, O’Brien Smith E, Ellis KJ 2000 Body composition during the first 2 years of life: an updated reference. Pediatr Res 47:578-585

23. Nuñez C, Kovera AJ, Pietrobelli A, Heshka S, Horlick M, Kehayias JJ, Wang Z, Heymsfield SB 1999 Body composition in children and adults by air displacement plethysmography Eur J Clin Nutr 53:382-387

24. Lohman TG 1992 Advances in body composition assessment. Current issues in exercise science, Monograph No. 3. Human Kinetics, Champaign, IL, pp 8-9 